OPEN ACCESS

Edited by:

Jayakumar Bose,

University of Adelaide, Australia

Reviewed by:

Pannaga Krishnamurthy,

National University of

Singapore, Singapore

Min Zhu,

Yangzhou University, China

${ }^{*}$ Correspondence: Kyung-Min Kim kkm@knu.ac.kr

Specialty section: This article was submitted to

Plant Abiotic Stress,

a section of the journal

Frontiers in Plant Science

Received: 13 March 2021

Accepted: 20 July 2021

Published: 13 August 2021

Citation:

Faroog $M$, Park J-R, Jang $Y-H$, Kim E-G and Kim K-M (2021) Rice

Cultivars Under Salt Stress Show

Differential Expression of Genes

Related to the Regulation of $\mathrm{Na}^{+} / \mathrm{K}^{+}$

Balance. Front. Plant Sci. 12:680131.

doi: 10.3389/fpls.2021.680131

\section{Rice Cultivars Under Salt Stress Show Differential Expression of Genes Related to the Regulation of $\mathrm{Na}^{+} / \mathrm{K}^{+}$Balance}

\author{
Muhammad Farooq, Jae-Ryoung Park, Yoon-Hee Jang, Eun-Gyeong Kim and \\ Kyung-Min Kim*
}

Division of Plant Biosciences, School of Applied Biosciences, College of Agriculture and Life Science, Kyungpook National University, Daegu, South Korea

Soil salinity is a major problem in agriculture because high accumulation of $\mathrm{Na}^{+}$ions in plants causes toxicity that can result in yield reduction. $\mathrm{Na}^{+} / \mathrm{K}^{+}$homeostasis is known to be important for salt tolerance in plants. $\mathrm{Na}^{+} / \mathrm{K}^{+}$homeostasis in rice (Oryza sativa L.) involves nine high-affinity $\mathrm{K}^{+}$transporter (HKT) encoding $\mathrm{Na}^{+}-\mathrm{K}^{+}$symporter, five OsNHX $\mathrm{Na}^{+} / \mathrm{H}^{+}$antiporters, and OsSOS1 $\mathrm{Na}^{+} / \mathrm{K}^{+}$antiporter genes. In the present study, we investigated various molecular and physiological processes to evaluate germination rate, growth pattern, ion content, and expression of OsHKT, OsNHX, and OsSOS1genes related to $\mathrm{Na}^{+} / \mathrm{K}^{+}$homeostasis in different rice genotypes under salt stress. We found a significant increase in the germination percentage, plant vigor, $\mathrm{Na}^{+} / \mathrm{K}^{+}$ratio, and gene expression of the OsHKT family in both the roots and shoots of the Nagdong cultivar and salt-tolerant cultivar Pokkali. In the roots of Cheongcheong and IR28 cultivars, $\mathrm{Na}^{+}$ ion concentrations were found to be higher than $\mathrm{K}^{+}$ion concentrations. Similarly, high expression levels of OsHKT1, OsHKT3, and OsHKT6 were observed in Cheongcheong, whereas expression levels of OsHKT9 was high in IR28. The expression patterns of OsNHX and OsSOS1 and regulation of other micronutrients differed in the roots and shoots regions of rice and were generally increased by salt stress. The OsNHX family was also expressed at high levels in the roots of Nagdong and in the roots and shoots of Pokkali; in contrast, comparatively low expression levels were observed in the roots and shoots of Cheongcheong and IR28 (with the exception of high OsNHX1 expression in the roots of IR28). Furthermore, the OsSOS1 gene was highly expressed in the roots of Nagdong and shoots of Cheongcheong. We also observed that salt stress decreases chlorophyll content in IR28 and Pokkali but not in Cheongcheong and Nagdong. This study suggests that under salt stress, cultivar Nagdong has more salt-tolerance than cultivar Cheongcheong.

Keywords: $\mathrm{Na}^{+} / \mathrm{K}^{+}$homeostasis, cultivar Pokkali, cultivar IR28, high-affinity $\mathrm{K}^{+}$transporter family, sodium/proton exchangers family, salt overly sensitive 


\section{INTRODUCTION}

Rice is one of the most important staple foods for a least half the world's population and is considered a salinity-sensitive crop (Munns and Tester, 2008). Rice cultivation systems are threatened by the effects of climate change because many rice-growing areas are located in vulnerable regions (Masutomi et al., 2009). In particular, salinity hazards are major problems in arid and semi-arid regions; irrigation is important for crop production in these regions and the main causes of salinity are salt-rich irrigation water, and improper management of irrigation (Plaut et al., 2013). Salinity stress can result in a 50\% yield loss; such a loss was previously estimated at around $6.9 \mathrm{dsm}^{-1}$ for rice (Van Genuchten and Gupta, 1993).

Plants can respond to various environmental stresses on an individual cellular level or synergistically as a whole organism. Salinity stress reduces plants growth rates and can be distinguished by measuring effects immediately upon addition of salt or after several days to weeks (Roy et al., 2014). The cytosol of plant cells normally contains $100-200-\mathrm{mM} \mathrm{K}^{+}$and $1-10-\mathrm{mM}$ $\mathrm{Na}^{+}$; this $\mathrm{Na}^{+} / \mathrm{K}^{+}$quotient is a requisite for many cellular metabolic activities. Cytosolic $\mathrm{Na}^{+}$ion homeostasis may be maintained by transporter genes such as OsHKT1, OsHKT2, and OsVHA in Oryza sativa L. indica cvs Pokkali and BRRI Dhan29 (Kader et al., 2006). In Arabidopsis thaliana, overexpression of vacuolar $\mathrm{Na}^{+} / \mathrm{H}^{+}$antiporter can promote plant growth and development in soil when it is watered with up to $200-\mathrm{mM}$ sodium chloride (Apse et al., 1999).

In a previous study, it was proposed that a salt-stress-elicited calcium signal activates a protein kinase complex consisting of the myristoylated calcium-binding protein salt overly sensitive (SOS) 3 and the serine/threonine protein kinase SOS2; this protein kinase complex then phosphorylates and activates the plasma membrane $\mathrm{Na}^{+} / \mathrm{H}^{+}$antiporter SOS1 (Zhu, 2003). The susceptibility of rice to salinity stress varies with growth stage, but it can cause reductions in final germination percentage, speed of germination, germination energy percentage, and lead to decreased root and shoot lengths and reduced dry matter (Ologundudu et al., 2014).

The O. sativa cultivar Nipponbare possesses nine $H K T$ genes in its genome, with two considered pseudogenes (Garciadeblás et al., 2003). These transporters have also been identified in Arabidopsis (Mäser et al., 2002), wheat (Schachtman and Schroeder, 1994; Gassmann et al., 1996), common ice plant (AAK52962) (Su et al., 2003), eucalyptus (Liu et al., 2001), and rice (Horie et al., 2001; Golldack et al., 2002). The salt tolerance of plants may depend on HKT transporters, which play critical roles in regulating $\mathrm{Na}^{+}$homeostasis because they mediate $\mathrm{Na}^{+}$-specific or $\mathrm{Na}^{+}-\mathrm{K}^{+}$transport (Garciadeblás et al., 2003). The antiporter genes OsNHX1 to OsNHX5 have also been identified in rice (Fukuda et al., 2011). Across the plasma membrane, $\mathrm{Na}^{+} / \mathrm{H}^{+}$antiporters catalyze the exchange of $\mathrm{Na}^{+}$ for $\mathrm{H}^{+}$that regulates internal $\mathrm{PH}$, cell volume, and sodium levels in the cytoplasm. Antiporters are mainly found in yeast, bacteria, animals, and plants with localization typically in the plasma membrane (Orlowski and Grinstein, 1997) and organelles including the perivacuolar compartment (Nass and Rao, 1998) (Figure 1).

$\mathrm{Na}^{+} / \mathrm{K}^{+}$-ATPase or $\mathrm{Na}^{+}$-ATPase are absent from plant cells but act to omit $\mathrm{Na}^{+}$from animal and fungal cells (Axelsen and Palmgren, 2001). In plants, $\mathrm{H}^{+}$-ATPase and $\mathrm{H}^{+}$-inorganic pyrophosphatase are the primary active transporters that induce an $\mathrm{H}^{+}$-motive force, whereas the $\mathrm{Na}^{+} / \mathrm{H}^{+}$antiporter is the main transporter of $\mathrm{Na}^{+}$(Hasegawa et al., 2000). Maintenance of intracellular ion concentrations is essential for ion homeostasis; under salt stress, $\mathrm{Na}^{+}$can enter into plant cells via several pathways and may become harmful to cytosolic enzymes at high concentrations. Therefore, it is essential that plant cells maintain high and low $\mathrm{K}^{+}$and $\mathrm{Na}^{+}$concentrations in the cytosol, respectively, and that they release excessive $\mathrm{Na}^{+}$or collect it in vacuoles (Taiz and Zeiger, 2002). In A. thaliana, $\mathrm{Na}^{+} / \mathrm{H}^{+}$ antiporters, encoded by the AtSOS1 gene, help to catalyze $\mathrm{Na}^{+}$ efflux in the plasma membrane (Shi et al., 2000, 2002).

The solubility of micronutrients such as $(\mathrm{Cu}, \mathrm{Mn}, \mathrm{Zn}, \mathrm{Fe}$, and Mo) is generally low, in both saline and sodic soil, and plants growing on such soils often experience deficiency of these elements but not in all cases (Page, 1996). Under salt stress, maize is grown both in solution culture, and soil (Izzo et al., 1991; Rahman et al., 1993), show a decrease in the concentration of $\mathrm{Cu}$ ion in the leaf and stem parts, but on the other hand salinity stress, substantially increased leaf $\mathrm{Cu}$ in hydroponically-grown tomatoes (Izzo et al., 1991). Most of the studies suggested that salt stress decreases Mn level in corn shoot tissue (Izzo et al., 1991; Rahman et al., 1993). However, some studies, show that salinity had no effect (Al-Harbi, 1995) or increase the Mn level in leaf or shoot tissue of tomato (Niazi and Ahmed, 1984). Most of the studies demonstrate that salinity stress, increase $\mathrm{Zn}$ concentration in shoot tissue such as in maize (Rahman et al., 1993), tomato (Knight et al., 1992), and citrus (Ruiz et al., 1997). But in some studies, it was not affected (Izzo et al., 1991), or on the other hand, Zn concentration was found to decrease in the case of cucumber leaves (Al-Harbi, 1995). Previous study reported that under salt stress, 12 soybean cultivars show a higher level of $\mathrm{Fe}, \mathrm{Mn}, \mathrm{Cu}$, and $\mathrm{Zn}$ in the region of the roots compared with those in leaves and stem (Tunçturk et al., 2008). In a previous study, it was reported that salinity stress, did not affect on grapevine Shoot $\mathrm{Ca}$ and $\mathrm{Mg}$, trunk $\mathrm{P}$, and $\mathrm{Mg}$, and root $\mathrm{P}, \mathrm{Ca}$, and $\mathrm{Mg}$ concentration. Some studies suggested that salt stress has an antagonistic effect on $\mathrm{Ca}^{+2}, \mathrm{~K}^{+}, \mathrm{Fe}, \mathrm{Mn}, \mathrm{P}$, and $\mathrm{Zn}$ but has a synergistic effect on Nitrogen (N) and Mg in rice crops (Jung et al., 2009; García et al., 2010).

In the present study, we compared two famous cultivars of the plant molecular breeding lab at Kyungpook National University, South Korea, namely Nagdong and Cheongcheong, with the salt-tolerant variety Pokkali and salt-sensitive variety IR28. We conducted molecular and physiological analyses of these four rice genotypes to identify the relative salt tolerance and sensitivity of the cultivars from the plant molecular breeding lab. The findings of this study could help develop new salt-tolerant or -sensitive cultivars via CRISPR/Cas9 knockout or overexpression methods in future studies. 


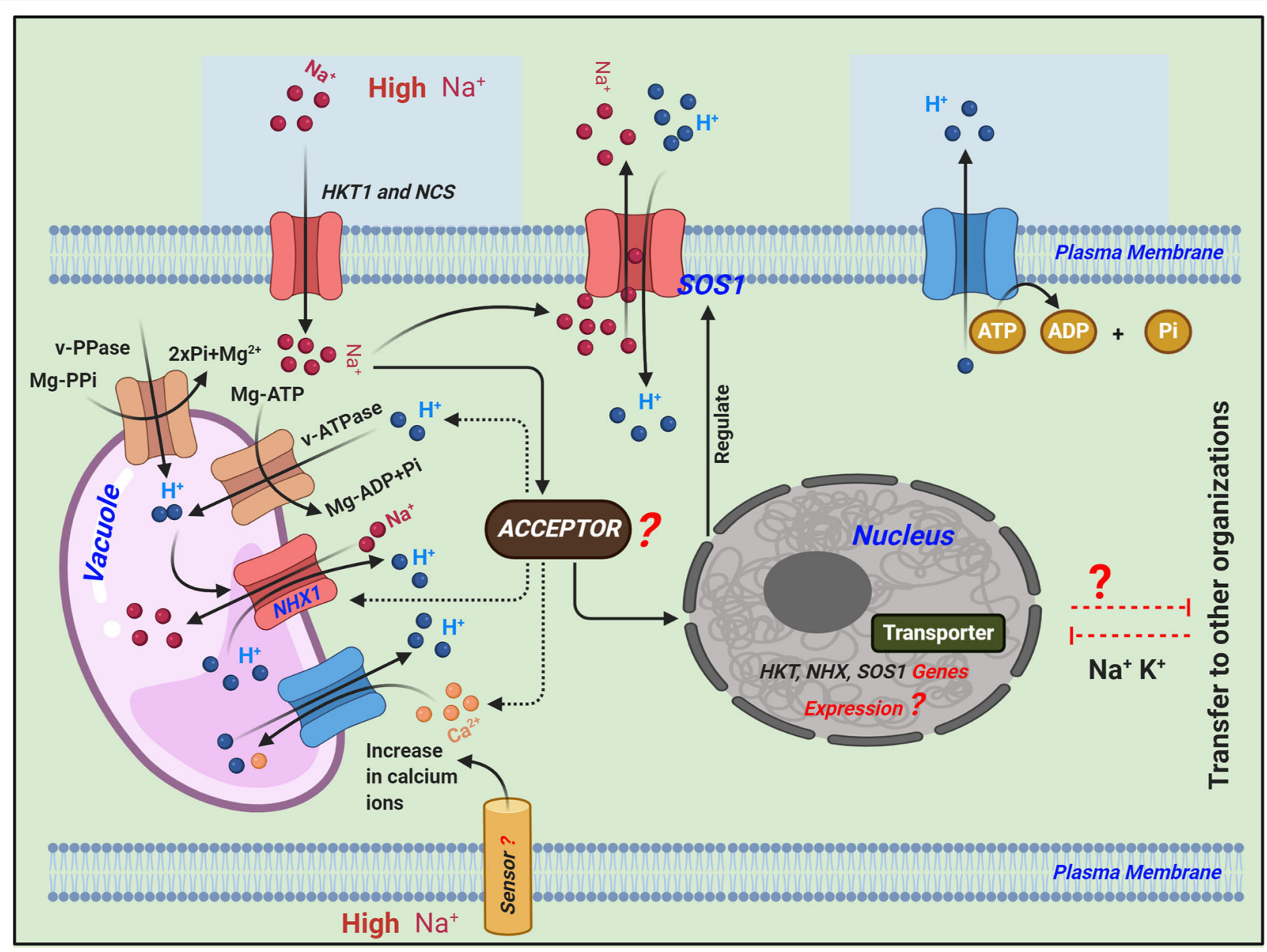

FIGURE 1 | Schematic representation of the transport regulatory mechanisms of $\mathrm{Na}^{+}$in plants under salinity stress adapted from (Roy et al., 2014; Zhang et al., 2018). Different signaling pathways regulate the expression of ion homeostasis-related genes: high-affinity $\mathrm{K}^{+}$transporter (HKT1) plays a key role in maintaining $\mathrm{Na}^{+}$ homeostasis and mediating $\mathrm{Na}^{+}$-specific transport or $\mathrm{Na}^{+}-\mathrm{K}^{+}$transport. Salt overly sensitive 1 (SOS1) plasma membrane $\mathrm{Na}^{+} / \mathrm{H}^{+}$antiporter exports intracellular $\mathrm{Na}^{+}$ to the extracellular space. Sodium/proton exchangers (NHX1) in the tonoplast can exchange $\mathrm{Na}^{+}$for protons, resulting in the removal of ions from the cytosol into the vacuole or extracellular space, which thereby minimizes cytotoxicity. While balancing the $\mathrm{Na}^{+}$in the cytoplasm, both of these $\mathrm{Na}^{+} / \mathrm{H}^{+}$antiporters, i.e., SOS1 and $\mathrm{NHX1}$, convert $\mathrm{H}^{+}$in the extracellular and vacuolar spaces to the cytoplasm, and excess $\mathrm{H}^{+}$in the cytoplasm is transported to the extracellular space via the consumption of energy (ATP is converted to ADP + Pi).

\section{MATERIALS AND METHODS}

Four different rice (O. sativa) genotypes Pokkali (Gyehwa20), IR28, Cheongcheong, and Nagdong were provided by the plant molecular breeding lab of Kyungpook National University. Pokkali (Gyehwa-20) is a unique salt-resistant cultivar that is cultivated in water-logged coastal regions, whereas IR28 is salt-sensitive. The cultivars Cheongcheong and Nagdong were used for comparison; "Cheongcheong (IT228761, IT number is a resource number managed by the National Academy of Agricultural Sciences of Rural Development Administration, Korea)" was established in 1974, YR675153-2-2, a sister line of "Miryang 29," which is a high-quality and -yield, to cultivate a new variety of disease resistance, high quality, safety and high yield. "Nagdong (IT006182)" was an artificial crossing in 1968 with a copy of Mineyudaka, a Japanese-type virus-resistant variety, as a model of "Nonglim 6" at the Yeungnam Agricultural Research Institute (Milyang, Gyungsnagnam-do, Korea) in order to cultivate a variety of safe virus-resistant varieties. These are two famous cultivars of the plant molecular lab from which the double haploid population consists of 133 lines that were derived from 2010 to 2012 (Yun et al., 2014) at Gunwi-gun near Kyungpook National University.

\section{Seed Germination Test}

Rice seeds of the four different genotypes were surface sterilized with $70 \%$ ethanol and $1 \%(\mathrm{v} / \mathrm{v})$ sodium hypochlorite solution for $30 \mathrm{~min}$ and afterward rinsed three times with deionized water. Small Petri dishes $(\sim 9 \mathrm{~cm}$ in diameter) containing autoclaved filter paper were used for germination tests; 15 seeds were placed in each Petri dish to give three replicates for each cultivar. Salt solutions of $0,100,150,200,300$, and $400 \mathrm{mM}$ were used in 
the germination tests. Each Petri dish was fixed with plastic paraffin film and placed inside a growth chamber with a $12 \mathrm{~h}$ light $/ 12 \mathrm{~h}$ dark photoperiod at $30^{\circ} \mathrm{C}$ in the light and $25^{\circ} \mathrm{C}$ in the dark. Relative humidity was maintained at $60 \%$ inside the growth chamber. The salt stress treatment lasted for two weeks. Seeds were considered to have germinated when the radical was protruding from the seed coat. Germinated seeds were counted after each week.

\section{Growth Conditions and Salt Treatment}

Clean and strong seeds of the four different rice cultivars were selected for germination and incubated for 4 days at $33^{\circ} \mathrm{C}$ using small plastic bags previously punched with a screw to allow entry and exist of water inside the incubator. Uniformly germinated seeds were selected and cultivated for 5 weeks in pots containing soil in a greenhouse at $20-25^{\circ} \mathrm{C}$ with a $10 \mathrm{~h}$ light/ $14 \mathrm{~h}$ of dark photoperiod to give three replicates for each cultivar. Before salinity stress, soil clay was kept overnight, and afterward filter the clay soil using filter paper and measure $\mathrm{pH} 6.5$ using a $\mathrm{pH}$ meter for $1 \mathrm{~kg}$ of soil. After 5 weeks, we treated the rice cultivars with $150 \mathrm{mM} \mathrm{NaCl}$ for 7 days. The rice plants were watered daily with $150 \mathrm{~mL}$ of brine solution. After salinity stress, the rice plants were washed five times with tap water and threetime with distilled water afterward kept for $30 \mathrm{~min}$ in $150 \mathrm{mM}$ $\mathrm{NaCl}$ solution. The samples were dried at $65^{\circ} \mathrm{C}$ for 2 days and determined the ion contents in both roots and shoot regions, and phenotypic data were also collected before and after the 7 days of salinity stress.

\section{Measurement of Chlorophyll Content}

Chlorophyll content was measured after salinity stress in control and treated cultivars using a SPAD device (Konica Minolta Sensing, Inc. Japan). From each replicate, five leaves were randomly selected and the lower apex, middle, and lower portions of the leaves were used to determine chlorophyll content.

\section{Quantitative Real-Time PCR Analysis}

Twenty germinating seeds of each rice genotype were grown for 14 days in pots containing soil up to the three-to-four-leaf stage. These plants were treated with $150-\mathrm{mM} \mathrm{NaCl}$ and then RNA was extracted from their roots and shoots regions after $0,8,24$, and $48 \mathrm{~h}$ using an RNeasy Plant Mini Kit (Qiagen, Germany) according to the manufacturer's instructions. A NanoDrop 2000 spectrophotometer (Thermo Scientific, Wilmington, DE, USA) was used to measure RNA concentrations. For first-strand cDNA synthesis, the qPCRBIO cDNA Synthesis Kit and $400 \mathrm{ng}$ of total RNA were used. For quantitative RT-PCR, we used the Eco Real-Time PCR system (Illumina, Inc., San Diego, CA, USA), 2X qPCRBIO SyGreen (www.pcrbio.com; London, UK), and primers specific to the selected genes (Table 1). OsActin1 (accession no. AB047313) was used as an internal reference gene for normalization.

\section{Analysis of Ion Content}

Roots and shoots of different rice genotypes from the greenhouse were used for ion determination as described by Rus et al.
(2001). Briefly, samples were dried at $65^{\circ} \mathrm{C}$ for 2 days, and then ground in liquid nitrogen. Subsequently, $100 \mathrm{mg}$ of tissue powder was extracted with $10 \mathrm{~mL}$ of $0.1 \mathrm{~N} \mathrm{HNO} 3$ for $30 \mathrm{~min}$. Samples were filtered and $\mathrm{Na}^{+} / \mathrm{K}^{+}$ions and other micronutrients were analyzed using an ICP Spectrometer (I) (Optima 7300DV \& Avio500; PerkinElmer).

\section{Statistical Analyses}

Statistical analysis was performed for three replicates, where each replication was considered as a block and arranged in different Petri dishes or pots in the control conditions. The experiment was repeated twice. Differences among treatment means were evaluated using Duncan's multiple range test with significance set at $P<0.05$. Data analysis was conducted in SPSS (IMMSPSS Statistics, version 22, NC). Figures were produced using Graph Pad Prism version 5.0 (Graph Pad Software Inc., San Diego, USA).

\section{RESULTS}

\section{Salinity Effect on Seed Germination}

Among the four different rice genotypes, germination percentage and growth of rice seedlings gradually decreased as salt concentration increased (Figures 2A-C). After 7 days of salt stress, there was a significant increase in the percentage of seeds germinating in both Pokkali and Nagdong up to 200-mM $\mathrm{NaCl}$. A few seeds germinated under $300-\mathrm{mM} \mathrm{NaCl}$ in Nagdong, but at $400-\mathrm{mM} \mathrm{NaCl}$ Nagdong seeds failed to germinate. Seed germination was significantly higher in Pokkali than in the other three rice genotypes. Seed germination percentage was significantly higher in the salt-sensitive cultivar IR-28 at 200-mM $\mathrm{NaCl}$ than that in Cheongcheong, but IR-28 seed germination was lower than Nagdong seed germination (Figure 2B). In both Cheongcheong and IR-28, seed germination was completely inhibited in the presence of 300 and $400 \mathrm{mM}$ of $\mathrm{NaCl}$ with 7-14 days of treatment. However, more than $20 \%$ of seeds germinated in Pokkali with salt stress of $400 \mathrm{mM} \mathrm{NaCl}$ (Figures 2B,C).

\section{Growth and Chlorophyll Reduction Under Salinity Stress}

Growth was affected in all rice genotypes after 3, 5, and 7 days of salinity stress. The growth rate of all rice cultivars declined under $150-\mathrm{mM} \mathrm{NaCl}$ stress relative to the growth in the control (Figure 3). The growth rates of Cheongcheong, IR28, and Pokkali dramatically alter compared with growth in the control. However, Nagdong suffered a slight in growth under salinity stress when compared with salt-treated Cheongcheong, IR28, and Pokkali cultivars (Figure 3). Similarly, under salinity stress, the chlorophyll content of IR28 and Pokkali were significantly reduced compared with that in the control group. The highest chlorophyll content was recorded in Cheongcheong before and after salinity stress; similarly, Nagdong maintained its chlorophyll content under salt treatment. The chlorophyll contents of Cheongcheong, IR28, and Pokkali were significantly higher than that of Nagdong in the control groups; however, after salinity stress, the chlorophyll contents of all cultivars were statistically similar, except for those of Cheongcheong (Figure 3B). 
TABLE 1 | List of primers used for qRT-PCR analysis of different rice genotypes.

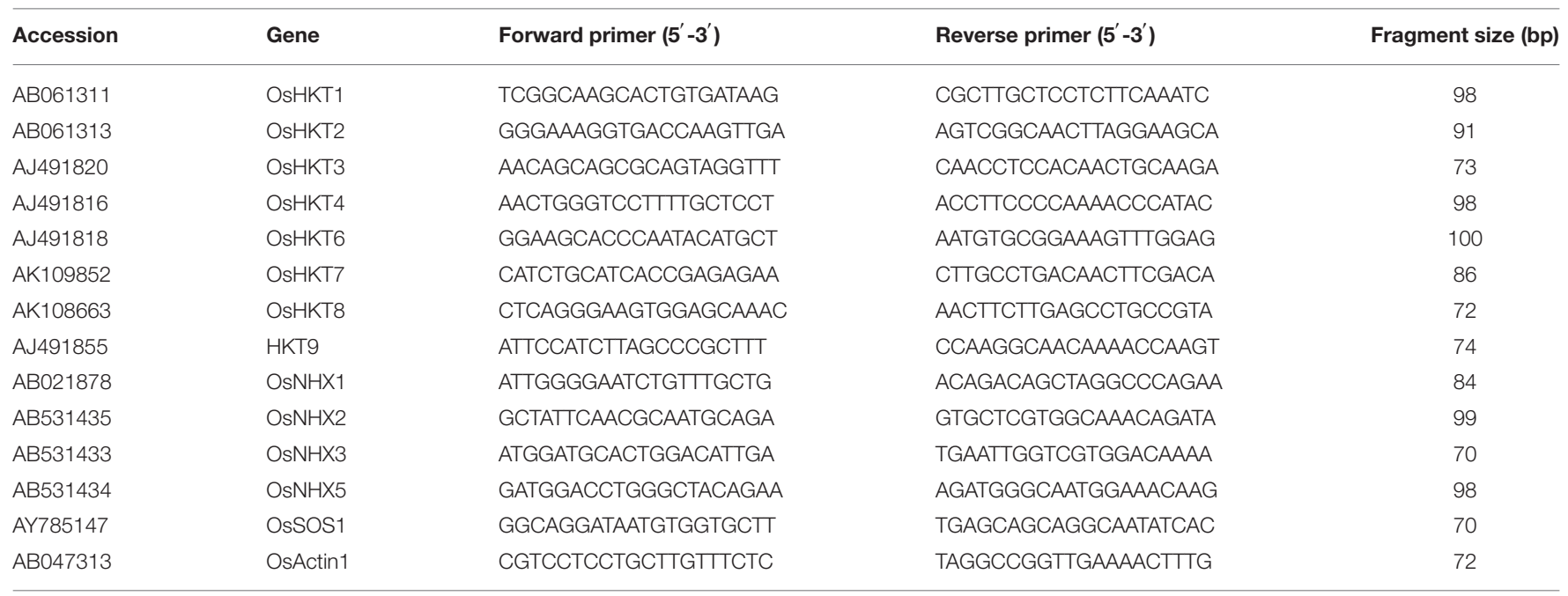

\section{Comparison of Ion Transport-Related Gene Expression Under Salt Stress Among Rice Genotypes}

The expression levels of eight ion transport regulation genes differed under salt stress according to real-time PCR (Figure 4). Among eight HKT genes, OsHKT1, OsHKT2, OsHKT3, OsHKT4, OsHKT6, and OsHKT9 were highly expressed in the roots and shoots regions of salt-tolerant cv. Pokkali (Figures 4A-E,H). OsHKT8 was highly expressed only in the shoots regions (Figure 4G). After salt stress treatment, OsHKT genes were differentially regulated in Pokkali rice; however, high expression of these genes was mainly found at 8 and $24 \mathrm{~h}$. Similarly, OsHKT1, OsHKT3, and OsHKT6 were upregulated in the root region of Cheongcheong at 8,24 , and $48 \mathrm{~h}$ (Figures $4 \mathrm{~A}, \mathrm{C}, \mathbf{E}$ ). However, all OsHKT family genes were downregulated in the Cheongcheong shoot regions at 8, 24, and $48 \mathrm{~h}$ (Figures 4A-H). The Nagdong cultivar showed the most significant upregulation of OsHKT1, OsHKT3, OsHKT4, and OsHKT7 at $48 \mathrm{~h}$ in the shoot regions (Figures 4A,C,D,E). In contrast, OsHKT6, OsHKT7, and OsHKT8 genes were upregulated at 8,24 , and $48 \mathrm{~h}$ in both the roots and shoots regions of Nagdong (Figures 4E-G). All OsHKT family genes were significantly downregulated in both the roots and shoots regions of salt-sensitive IR-28 except for OsHKT3 and OsHKT9, which were significantly upregulated in the roots region at 8, 24, and $48 \mathrm{~h}$ (Figures $\mathbf{4 C}, \mathbf{H}$ ).

Under salt stress treatment, OsNHX family genes were differentially expressed at different time points. OsNHX1 was significantly upregulated in both IR-28 and Pokkali, with maximum levels of expression observed at $48 \mathrm{~h}$ in the roots of IR-28 and at $24 \mathrm{~h}$ in the shoots of Pokkali (Figure 5A). Similarly, OsNHX2 was upregulated in both IR-28 and Pokkali, but high expression levels were observed at 8,24 , and $48 \mathrm{~h}$ in the shoots of Pokkali and at $24 \mathrm{~h}$ in IR-28 (Figure 5B). High expression of OsNHX2 was observed in the roots region of Nagdong at 8 and $24 \mathrm{~h}$ and IR-28 at 8, 24, and $48 \mathrm{~h}$ (Figure 5B). The expression of OsNHX3 was upregulated in the roots of Nagdong and Pokkali at
8 and $24 \mathrm{~h}$; in the shoots region, it was only upregulated in the Pokkali cultivar (Figure 5C). High expression of OsNHX5 was observed in both the roots and shoots regions of Pokkali at $48 \mathrm{~h}$ of stress (Figure 5D). On the other hand, OsNHX5 was highly expressed in the shoots of Cheongcheong at 8,24, and $48 \mathrm{~h}$ of salt stress (Figure 5D). In contrast, expression of OsSOS1 was significantly downregulated in the roots and shoots of both IR28 and Pokkali; however, OsSOS1 was significantly upregulated in the roots and shoots of both Nagdong and Cheongcheong at 8 , 24, and $48 \mathrm{~h}$ (Figure 5E).

\section{Comparative Analysis of Ion Content Under Salt Stress}

Under salt stress, we examined nine elements, namely $\mathrm{Na}^{+}, \mathrm{K}^{+}$, $\mathrm{Ca}^{2+}, \mathrm{Mg}^{2+}, \mathrm{Cu}^{2+}, \mathrm{Zn}^{2+}, \mathrm{Fe}^{2+}, \mathrm{Mn}^{2+}$, and $\mathrm{P}$, in the roots and shoots of both control and treated plants. These elements were differentially regulated in the rice genotypes under salt stress. After 7 days of $150-\mathrm{mM}$ salt stress, $\mathrm{Na}^{+}$, and $\mathrm{K}^{+}$ions were inversely regulated in the roots and shoots of control and treated plants: as $\mathrm{Na}^{+}$levels increased $\mathrm{K}^{+}$ions decreased and vice versa. Under salt stress, $\mathrm{Na}^{+}$content significantly increased in the roots of all four rice genotypes relative to levels in the control, whereas $\mathrm{K}^{+}$content decreased in the roots of Cheongcheong and Pokkali relative to content in the control (Table 2). On the other hand, in Nagdong and IR28, $\mathrm{K}^{+}$content was significantly higher than that in the control. In the respective roots of Cheongcheong and IR28, content of $\mathrm{Na}^{+}$increased by $\sim 748.35$ - and 2140.06fold, whereas $\mathrm{K}^{+}$ion content inversely decreased by 698.45 and 1443.72-fold. In Nagdong and Pokkali roots, $\mathrm{K}^{+}$content increased by $\sim 1069.88$ - and 3786.88 -fold, whereas $\mathrm{Na}^{+}$content decreased by 935.50 - and 3556.27-fold, respectively. Both $\mathrm{Na}^{+}$ and $\mathrm{K}^{+}$contents were significantly higher in salt-treated plant shoots than in control plant shoots. In treated plant shoots, $\mathrm{Na}^{+}$ and $\mathrm{K}^{+}$ions were present inversely, with $\mathrm{K}^{+}$ions found at significantly higher levels than those of $\mathrm{Na}^{+}$ions in all four rice genotypes. The content of $\mathrm{K}^{+}$ions was approximately $406.82-$, 


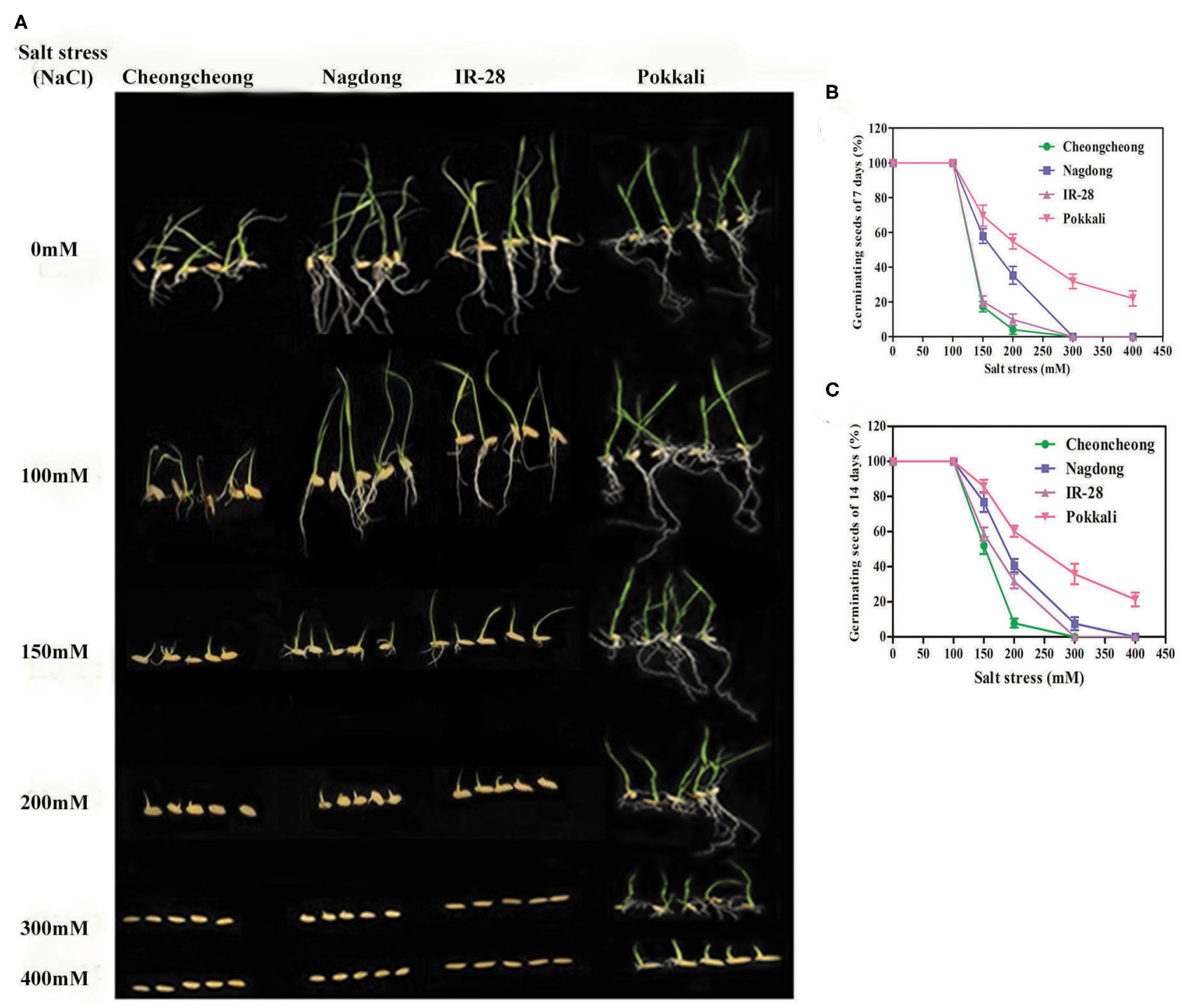

FIGURE 2 | Seed germination rate and seedling growth of different rice genotypes under salt stress. Various concentrations of salt stress were used to determine the seed germination and seedling growth represented in (A), (B), and (C).

2684.84-, 6365.42-, and 7562.18-fold higher than that of $\mathrm{Na}^{+}$ ion in the treated cultivars Cheongcheong, IR28, Nagdong, and Pokkali, respectively (Table 2.). In addition to $\mathrm{Na}^{+}$and $\mathrm{K}^{+}$ions, the uptake and transportation of other ions also differed in the roots and shoots of all four rice genotypes relative to that in the control. For example, compared with control plants, the content of $\mathrm{Ca}^{2+}$ decreased after salt stress in the roots of Nagdong and shoots of Pokkali, whereas $\mathrm{Mg}^{2+}$ content decreased in the roots of Cheongcheong. Both $\mathrm{Ca}^{2+}$ and $\mathrm{Mg}^{2+}$ content were increased in the roots and shoots of IR28, as well as in the shoots of Cheongcheong and Nagdong, and in the roots of Pokkali; in the shoots of Pokkali, only $\mathrm{Mg}^{2+}$ was increased. In addition, $\mathrm{Cu}^{2+}$ content increased in the roots and shoots of all rice genotypes after salt stress except in IR28 shoots. On the other hand, after salt stress and compared with the control, $\mathrm{Zn}^{2+}$ content increased in the roots and shoots of Nagdong and IR28, but was significantly decreased in the roots and shoots of Cheongcheong and Pokkali. Furthermore, the contents of $\mathrm{Fe}^{2+}, \mathrm{Mn}^{2+}$, and $\mathrm{P}$ were significantly increased in Cheongcheong and Nagdong shoots. In the roots of Cheongcheong, $\mathrm{Fe}^{2+}$ and $\mathrm{P}$ decreased, and in the roots of Nagdong $\mathrm{Mn}^{2+}$ decreased, all relative to levels in control plants. In the roots of IR28, the content of $\mathrm{Fe}^{2+}$, $\mathrm{Mn}^{2+}$, and $\mathrm{P}$ were increased; in the roots of Pokkali, these three elements were significantly decreased. However, in the shoots of IR28, $\mathrm{Mn}^{2+}$ was increased; in the shoots of Pokkali, $\mathrm{Fe}^{2+}$ and $\mathrm{P}$ were increased. 


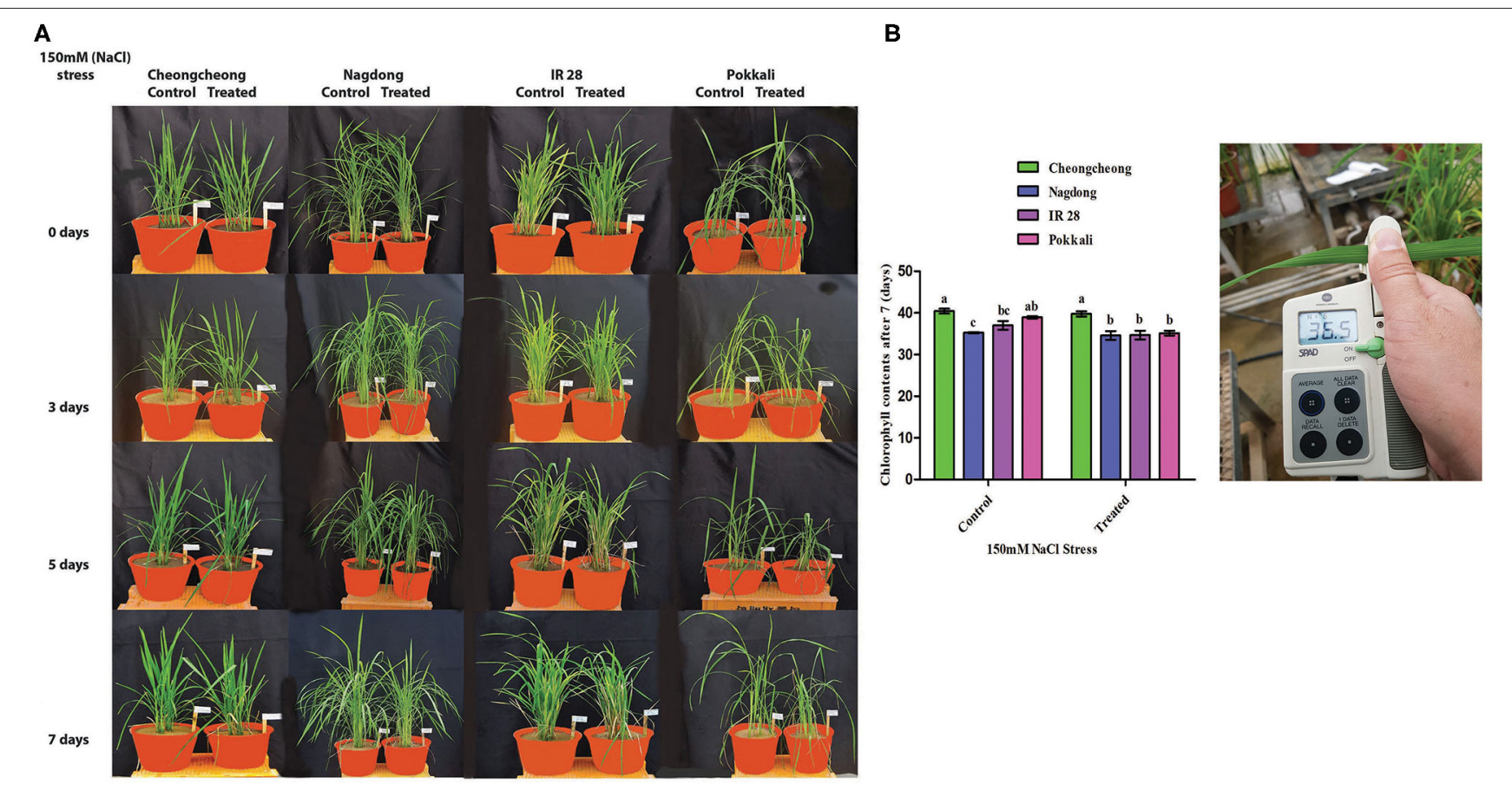

FIGURE 3 | Phenotypic representation of different rice genotypes under 150-mM salinity stress in a greenhouse. (A) Effects of salt stress after 3 , 5, and 7 days; (B) Chlorophyll measurements before and after salinity stress.

\section{DISCUSSION}

\section{Salinity Inhibits Seed Germination and Reduces Rice Seedling Growth}

A previous study suggested that salinity stress up to $20 \mathrm{dS} \mathrm{m} \mathrm{m}^{-1}$ strongly inhibits rice seed germination, yield reduction, growth reduction in shoot and root length, and dry matter (Hakim et al., 2010). However, another study reported that rice is salt tolerant to some extent at germination and, in some cases, not significantly affected by salt up to $16.3 \mathrm{dS} \mathrm{m}^{-1}$ (Khan et al., 1997). In contrast, high concentrations of salinity affect the seedling stage of rice (Lutts et al., 1996). Our results demonstrate that $\mathrm{NaCl}$, treatment inhibits rice seed germination as well as seedling growth as salt concentrations increase. Furthermore, the high levels of germination were recorded in the salt-resistant Pokkali and plant molecular breeding lab Nagdong cultivars. Salt stress inhibits seed germination along with seedling growth, reduces photosynthesis levels, and promotes senescence (Tuteja et al., 2013). However, up to $100-\mathrm{mM} \mathrm{NaCl}$, the germination percentage was similar among the four tested rice genotypes.

\section{Salt Accumulation Leads to Reduced Growth Patterns and Chlorophyll Content}

Through several different processes, salinity reduces plant growth, which is related to the accumulation of salt in the shoots and/or roots. These effects can be experimentally distinguished within a minute to several days or weeks (Sirault et al., 2009). For example, salt stress reduces the growth of sugar beet (Ghoulam et al., 2002), cotton (Meloni et al., 2001), and tomato (RomeroAranda et al., 2001). To explore that salinity stress decreases the growth rate and chlorophyll content. In our study, we observed growth reduction in all genotypes under salt stress. High salt uptake mostly causes necrosis and leaf tip burn in plants (Wahome et al., 2001). Previous studies suggest that both growth and photosynthesis are interdependent; therefore, environmental stress affecting growth also affects photosynthesis (Dubey, 1996; Taiz and Zeiger, 1998). Another report has indicated that salt stress reduces photosynthesis rates mainly via water potential (Cushman et al., 1989). Our results demonstrate that, under salinity stress, chlorophyll content was decreased in IR28 and Pokkali compared with the content in Cheongcheong and Nagdong, all relative to control plant levels.

\section{Differential Expression of Ion \\ Transport-Related Genes in Rice Genotypes Under Salt Stress}

We detailed the differential pattern of gene expression of $H K T$, NHX, and SOS1 in the roots and shoots regions of rice genotypes under salt stress. In the current study, we found high induction of OsHKT1 in the roots of Cheongcheong and Pokkali following 8 and $24 \mathrm{~h}$ of salt stress, although the degree of induction in the shoots of Nagdong and Pokkali was varied with time. However, in salinity stress, $\mathrm{Na}^{+}$ion competition at $\mathrm{K}^{+}$binding sites may contribute to $\mathrm{K}^{+}$deficiency (Maathuis and Amtmann, 1999) and thus might cause the high induction of OsHKT1 in rice genotypes observed here. Under a high level of $\mathrm{NaCl}$, there is another possibility that excess $\mathrm{Na}^{+}$entering the cytosol increases the ideal cytosolic $\mathrm{Na}^{+} / \mathrm{K}^{+}$ratio in cells which might recognize as a $\mathrm{K}^{+}$ deficiency, thus inducing OsHKT1 as suggested by Horie et al. (2001) in case of the $\mathrm{K}^{+}$deficiency. A previous study reported 


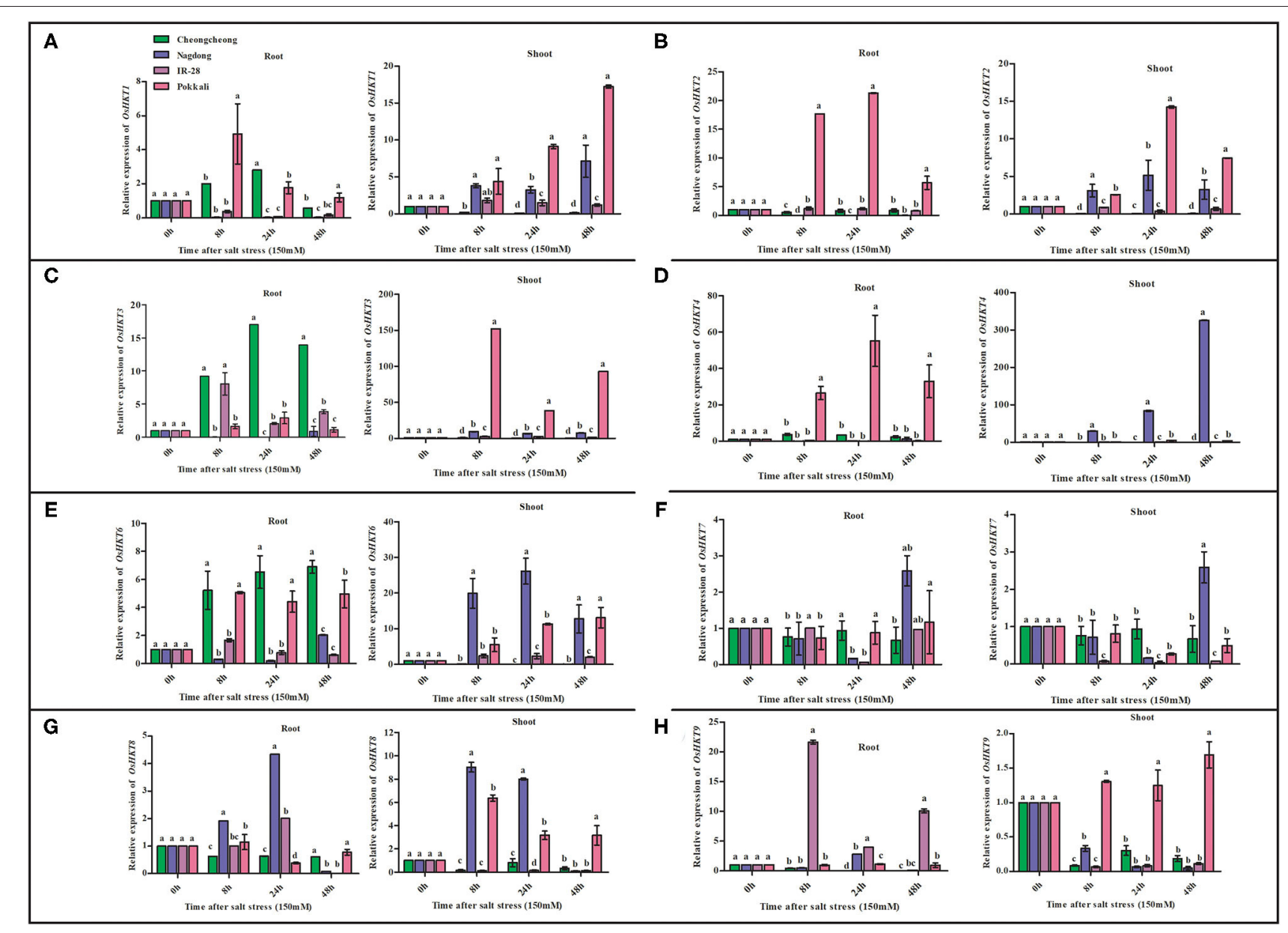

FIGURE 4 | Quantitative real-time PCR analyses of HKT family genes from root and shoot tissues of salt-tolerant and salt-sensitive rice varieties (Pokkali and IR28) and plant molecular breeding lab varieties (Cheongcheong and Nagdong) under salt stress. The expression pattern of OsHKT genes under 150 -mM NaCl stress is shown in (A-H). Different letters in the graphs indicate statistical differences among the treatments when compared with the control $(P<0.05$ by Duncan's multiple range test).

that $150-\mathrm{mM} \mathrm{NaCl}$ stress induced high levels of OsHKT1 in both the root and shoot tissues of salt-sensitive BRRI Dhan29, whereas salt-tolerant Pokkali showed high expression of OsHKT2 in shoots and lower expression in root tissue (Kader et al., 2006). Our results also suggest the involvement of OsHKT2 in the saltstress response, especially in salt-tolerant Pokkali. High induction of OsHKT2 was observed in Pokkali, which was 20-fold higher in the roots, 15-fold higher in the shoots, and 5-fold higher in the shoot of Nagdong.

Previous studies have reported tissue-specific localization of three members of each HKT subfamily: from subfamily 1 : AtHKT1;1 from Arabidopsis (Berthomieu et al., 2003; Horie et al., 2005), OsHKT1;5 from rice (Ren et al., 2005), and McHKT1 from ice plant (Su et al., 2003); for sub family 2: TaHKTT2;1 from wheat (Schachtman and Schroeder, 1994), OsHKTT2;1 (Golldack et al., 2002; Kader et al., 2006; Horie et al., 2007), and OsHKT2;2 (Kader et al., 2006). All results emphasize that HKT transporter is actively expressed in tissues (e.g., the root epidermis and cortex, xylem and phloem, and vascular bundle region). Expression patterns of subfamily 1 transporters have been consistently found in the vasculature and rarely in other tissues, whereas expression of subfamily 2 transporters has mainly been observed in root periphery cells and often tissues in or near to the plant vasculature (Horie et al., 2007). OsHKT1;1 and OsHKT1;3 are mostly expressed in bulliform cells, enlarged epidermal, cells, and are responsible for both $\mathrm{Na}^{+}$and $\mathrm{K}^{+}$ permeability; thus, HKT transporter expression is not restricted to root periphery cells and vascular regions (Jabnoune et al., 2009). Rice has a total of nine HKT transporter genes, which raises interesting questions about the functional diversity within this transporter family (Garciadeblás et al., 2003).

Our result demonstrates differentially induction of $H K T$ family genes in the roots and shoots of the four tested rice genotypes, OsHKT1 was highly expressed in the roots of Cheongcheong and Pokkali and the shoots of Nagdong and Pokkali after 24 and $48 \mathrm{~h}$. Additionally, upregulation OsHKT3, OsHKT4, and OsHKT6, 7-17-fold increases in expression were found in the roots of Cheongcheong after 24 and $48 \mathrm{~h}$ of stress, whereas OsHKT6, OsHKT7, OsHKT8, and OsHKT9 were downregulated in both the roots and shoots of Cheongcheong. 


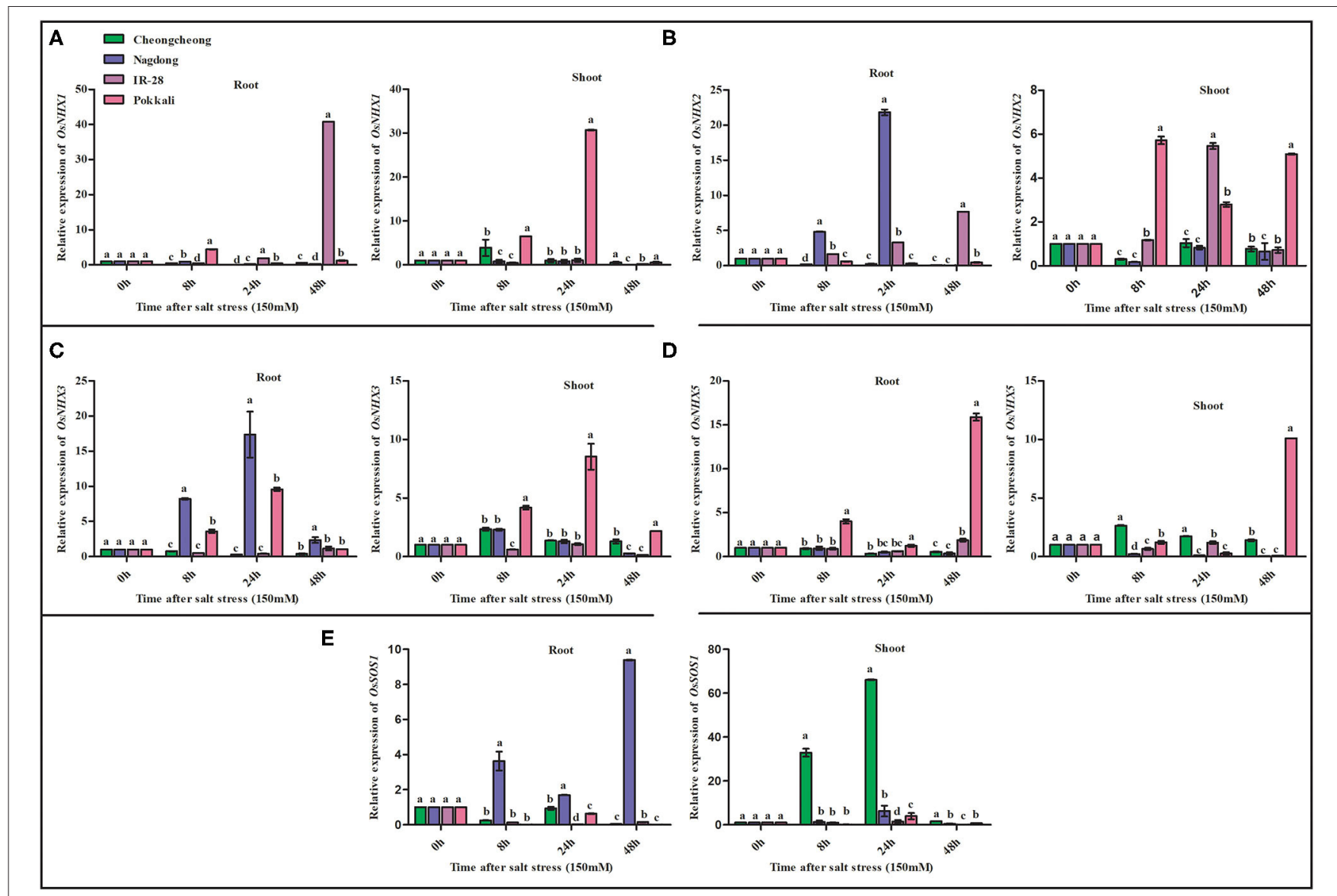

FIGURE 5 | Quantitative real-time PCR expression analysis of NHX family and OsSOS1 genes from the root and shoot tissues of different rice genotypes. The expression patterns of OsNHX and OsSOS1 genes under 150-mM NaCl stress are shown in (A-E). Different letters in the graphs indicate statistical differences among the treatments when compared with the control group $(P<0.05$ by Duncan's multiple range test).

In the salt-sensitive cultivar IR28, all OsHKT family genes were downregulated in both the roots and shoots (compared with control expression), except for OsHKT3, OsHKT8, and OsHKT9 expression in the roots.

Golldack et al. (2002) previously reported that OsHKT1 transcription is downregulated in the root tips of Pokkali and IR29 under salt stress. We found a consistent difference in expression of OsHKT family genes among the tested rice cultivars; however, high expression of OsHKT3, OsHKT8, and OsHKT9 was observed in the shoots of Pokkali under salt stress while low expression of OsHKT3, OsHKT7, OsHKT8, and OsHKT9 was observed in the roots. The lab cultivar Nagdong showed the highest expression of OsHKT1, OsHKT2, OsHKT4, OsHKT6, and OsHKT8 in the shoot region while expression levels in the roots were lowest (except for expression of OsHKT7 and OsHKT8 genes) under salt stress.

In a previous study, OsNHX proteins were placed into two subgroups: OsNHX1-OsNHX4 and OsNHX5. These play important roles in the response to salt stress; for example, OsNHX1, OsNHX2, OsNHX3, and OsNHX5 can suppress $\mathrm{Na}^{+}$, $\mathrm{Li}^{+}$, and $\mathrm{K}^{+}$that are localized in the tonoplast (Fukuda et al., 2011). Another study reported that $n h x 1$ mutants exhibit lower $\mathrm{K}^{+}$content in both the shoots and roots compared with that found in the wild type (Pardo et al., 2006). Under stress conditions, transcription levels of OsNHX1 in the shoots are higher than those in the roots, whereas transcription levels of OsNHX5 are higher in the roots than those in the shoots (Fukuda et al., 2004, 2011). We also found that expression of OsNHX family genes was regulated differentially in the roots and shoots of the four tested rice genotypes. High expression of OsNHX1 was observed in the roots of IR28 and Pokkali, but expression was higher in the shoots of Pokkali. Similarly, OsNHX2 was highly expressed in the roots of Nagdong and IR28, whereas expression of this gene in the shoots was found to be higher in IR28 and Pokkali after 8, 24, and 48 h of stress. Zhang et al. (2018) previously reported high expression of OsNHX3 and OsNHX4 in the salt-tolerant $J Y G Y-1$ rice variety under salt stress. Our results also indicate that expression of OsNHX3 and OsNHX5 was relatively high in roots and shoots after 24 and $48 \mathrm{~h}$ of salt stress in the salt-tolerant variety Pokkali. Similarly, in the roots of Nagdong, high expression levels of OsNHX3 were observed after $24 \mathrm{~h}$ of salinity stress, whereas expression of $\mathrm{OsNHX} 3$ and OsNHX 5 was relatively low in the shoots of Cheongcheong after $8 \mathrm{~h}$ of salt stress.

The SOS pathway is involved in maintaining the $\mathrm{Na}^{+} / \mathrm{K}^{+}$ratio in cells; the SOS1 $\mathrm{Na}^{+} / \mathrm{K}^{+}$antiporter reduces accumulation of 
TABLE 2 | Inductively coupled plasma spectroscopy analysis [in ppm (mg/kg)] conducted under 150-mM NaCl stress.

\begin{tabular}{|c|c|c|c|c|c|c|c|c|}
\hline \multirow[b]{2}{*}{ Ions } & \multicolumn{4}{|c|}{ Cheongcheong } & \multicolumn{4}{|c|}{ Nagdong } \\
\hline & $\begin{array}{c}\text { Control } \\
\text { root }\end{array}$ & $\begin{array}{c}\text { Treated root } \\
150 \mathrm{mM}(\mathrm{NaCl})\end{array}$ & $\begin{array}{l}\text { Control } \\
\text { shoot }\end{array}$ & $\begin{array}{l}\text { Treated shoot } \\
150 \mathrm{mM}(\mathrm{NaCl})\end{array}$ & $\begin{array}{l}\text { Control } \\
\text { root }\end{array}$ & $\begin{array}{c}\text { Treated root } \\
150 \mathrm{mM}(\mathrm{NaCl})\end{array}$ & $\begin{array}{l}\text { Control } \\
\text { shoot }\end{array}$ & $\begin{array}{l}\text { Treated shoot } \\
150 \mathrm{mM}(\mathrm{NaCl})\end{array}$ \\
\hline $\mathrm{Na}^{+}$ & $7162.76 \pm 167.75^{a}$ & $13566.1 \pm 748.35^{b c}$ & $886.88 \pm 6.43^{d}$ & $9438.99 \pm 104.51^{\mathrm{cd}}$ & $2331.19 \pm 30.89^{b}$ & $16045.18 \pm 935.5^{b}$ & $817.76 \pm 56.51^{d}$ & $11543.04 \pm 2034.33^{\mathrm{bcd}}$ \\
\hline $\mathrm{K}^{+}$ & $47322.37 \pm 1492.07^{a}$ & $13311.39 \pm 698.45^{\mathrm{bc}}$ & $15703.47 \pm 240.86^{d}$ & $32020.11 \pm 406.82^{\mathrm{a}}$ & $7205.56 \pm 34.78^{e}$ & $17962.58 \pm 1069.88^{b}$ & $5852.8 \pm 339.86^{e}$ & $35696.97 \pm 6365.42^{a}$ \\
\hline $\mathrm{Ca}^{2+}$ & $1216.82 \pm 47.38^{f}$ & $2128.53 \pm 64.67^{\dagger}$ & $1905.42 \pm 12.12^{\mathrm{d}}$ & $3398.85 \pm 57.98^{b}$ & $4282.03 \pm 25.9^{a}$ & $3784.76 \pm 58.75^{a}$ & $1035.65 \pm 55.42^{9}$ & $2629.04 \pm 38.74^{e}$ \\
\hline $\mathrm{Mg}^{2+}$ & $3718.77 \pm 137.94^{b}$ & $3129.29 \pm 40.79^{c}$ & $1010.24 \pm 9.95^{\dagger}$ & $2611.5 \pm 90.12^{d}$ & $2795.77 \pm 10.81^{c}$ & $3542.99 \pm 31.88^{b}$ & $773.18 \pm 46.97^{9}$ & $2200.65 \pm 44.84^{e}$ \\
\hline $\mathrm{Cu}^{2+}$ & $53.69 \pm 3.01^{a}$ & $54.58 \pm 1.75^{a}$ & $12.9 \pm 0.08^{d}$ & $27.66 \pm 0.14^{d}$ & $19.21 \pm 0.18^{c}$ & $23.55 \pm 0.11^{\dagger}$ & $6.46 \pm 0.45^{\mathrm{e}}$ & $25.71 \pm 0.13^{e}$ \\
\hline $\mathrm{Zn}^{2+}$ & $109.02 \pm 1.8^{\mathrm{a}}$ & $108.57 \pm 3.25^{a}$ & $30.43 \pm 1.16^{\mathrm{e}}$ & $63.16 \pm 0.28^{\mathrm{cd}}$ & $66.99 \pm 8.6^{c}$ & $84.25 \pm 1.36^{\mathrm{b}}$ & $16.26 \pm 3.8^{f}$ & $58.76 \pm 3.05^{d}$ \\
\hline $\mathrm{Fe}^{2+}$ & $478.08 \pm 20.84^{d}$ & $466.9 \pm 13.22^{\mathrm{g}}$ & $710.89 \pm 0.63^{b}$ & $1226.89 \pm 14.53^{\mathrm{c}}$ & $471.12 \pm 3.12^{d}$ & $800.45 \pm 1.4^{e}$ & $627.24 \pm 35.79^{c}$ & $1464.06 \pm 6.94^{b}$ \\
\hline $\mathrm{Mn}^{2+}$ & $2524.12 \pm 131.26^{c}$ & $7949.05 \pm 106.31^{a}$ & $269.05 \pm 7.81^{\text {de }}$ & $4223.22 \pm 174.5^{d}$ & $9425.34 \pm 164.28^{a}$ & $7646.2 \pm 83.68^{b}$ & $229.48 \pm 48.21^{e}$ & $864.62 \pm 23.16^{f}$ \\
\hline $\mathrm{P}$ & $4115.76 \pm 115.19^{a}$ & $1596.51 \pm 31.11^{9}$ & $1816.64 \pm 7.19^{d}$ & $3616.16 \pm 25.89^{a}$ & $1616.29 \pm 8.25^{e}$ & $2931.81 \pm 16.46^{d}$ & $742.49 \pm 57.3^{f}$ & $3427.35 \pm 4.53^{b}$ \\
\hline \multicolumn{4}{|c|}{ IR28 } & & \multicolumn{4}{|c|}{ Pokkali } \\
\hline $\mathrm{Na}^{+}$ & $1863.74 \pm 117.75^{\mathrm{bc}}$ & $30116.15 \pm 2140.06^{a}$ & $1158.76 \pm 48.31^{\mathrm{cd}}$ & $7430.18 \pm 952.49^{d}$ & $7837.89 \pm 1059.42^{\mathrm{a}}$ & $34243.13 \pm 3556.27^{a}$ & $1830.72 \pm 38.83^{\mathrm{bc}}$ & $10427.33 \pm 2230.61^{\mathrm{cd}}$ \\
\hline $\mathrm{K}^{+}$ & $5271.43 \pm 206.6^{e}$ & $20496.77 \pm 1443.72^{b}$ & $17127.61 \pm 421.77^{d}$ & $19987.48 \pm 2684.11^{b}$ & $42294 \pm 5328.69^{b}$ & $37697.25 \pm 3786.88^{a}$ & $28045.71 \pm 11.87^{\circ}$ & $35329.41 \pm 7562.18^{\mathrm{a}}$ \\
\hline $\mathrm{Ca}^{2+}$ & $1053.14 \pm 46.449$ & $2010.48 \pm 25.65^{9}$ & $1504.71 \pm 16.81^{\mathrm{e}}$ & $2049.78 \pm 14.73^{\mathrm{fg}}$ & $2586.02 \pm 69.3^{c}$ & $3017.59 \pm 43.75^{d}$ & $3256.09 \pm 2.43^{b}$ & $3153.01 \pm 28.96^{c}$ \\
\hline $\mathrm{Mg}^{2+}$ & $1144.26 \pm 54.67^{e f}$ & $3513.83 \pm 2.51^{b}$ & $1242.62 \pm 48.19^{\mathrm{e}}$ & $1538.29 \pm 45.18^{f}$ & $3907.19 \pm 62.24^{a}$ & $4482.88 \pm 60.05^{a}$ & $1833.98 \pm 16.14^{d}$ & $2099.7 \pm 43.35^{e}$ \\
\hline $\mathrm{Cu}^{2+}$ & $19.02 \pm 0.53^{c}$ & $31.02 \pm 0.04^{c}$ & $14.79 \pm 0.06^{d}$ & $13.34 \pm 0.03^{h}$ & $26.75 \pm 0.39^{b}$ & $35.56 \pm 0.05^{b}$ & $13.9 \pm 0.23^{\mathrm{d}}$ & $16.16 \pm 0.18^{g}$ \\
\hline $\mathrm{Zn}^{2+}$ & $27.92 \pm 0.59^{e}$ & $64.35 \pm 1.51^{\mathrm{c}}$ & $24.35 \pm 0.65^{e}$ & $32.94 \pm 1.36^{\mathrm{e}}$ & $87.07 \pm 0.51^{b}$ & $59.46 \pm 2.22^{\mathrm{cd}}$ & $42.86 \pm 1.2^{\mathrm{d}}$ & $30.74 \pm 2.83^{\mathrm{e}}$ \\
\hline $\mathrm{Fe}^{2+}$ & $181.97 \pm 0.05^{e}$ & $274.86 \pm 5.4^{h}$ & $708.76 \pm 12.18^{b}$ & $697.62 \pm 1.51^{\dagger}$ & $1986.29 \pm 45.56^{a}$ & $1051.35 \pm 5.99^{d}$ & $1981.8 \pm 15.78^{a}$ & $3340.17 \pm 64.3^{a}$ \\
\hline $\mathrm{Mn}^{2+}$ & $2345.94 \pm 113.99^{c}$ & $3138.09 \pm 49.03^{e}$ & $220.81 \pm 1.05^{e}$ & $547.4 \pm 205.78^{9}$ & $8454.1 \pm 268.94^{b}$ & $6772.82 \pm 76.93^{c}$ & $545.7 \pm 6.98^{d}$ & $218.18 \pm 15.52^{h}$ \\
\hline$P$ & $461.38 \pm 16.68^{9}$ & $1704.81 \pm 30.75^{f}$ & $1841.56 \pm 19.5^{d}$ & $1752.12 \pm 19.72^{f}$ & $2643.12 \pm 64.05^{b}$ & $2321.95 \pm 7.53^{\mathrm{e}}$ & $2364.91 \pm 8.34^{\mathrm{C}}$ & $2990.55 \pm 32.89^{c}$ \\
\hline
\end{tabular}

After 7 days of salt stress, $\mathrm{Na}^{+}, \mathrm{K}^{+}$and other micronutrients, such as $\mathrm{Ca}^{2+}, \mathrm{Mg}^{2+}, \mathrm{Cu}^{2+}, \mathrm{Zn}^{2+}, \mathrm{Fe}^{2+}, \mathrm{Mn}^{2+}$, and $\mathrm{P}$, were measured in the roots and shoots of both control and treated plants. Data \pm standard error are shown. Different letters after data $(a-h)$ indicate significant differences between salt treatments $(P<0.05$ by Duncan's multiple range test). 
$\mathrm{Na}^{+}$and improves salt tolerance in mutant cells (Shi et al., 2002). In Arabidopsis, the SOS1 genetic locus confers salt tolerance (Wu et al., 1996). In a previous study, high induction of OsSOS1 was observed under salt stress in the roots of cultivated and weedy rice (Zhang et al., 2018). In the present study, high expression of OsSOS1 was observed in the roots and shoots of both Cheongcheong and Nagdong cultivars after 8, 24, and $48 \mathrm{~h}$ of salt stress; in contrast, OsSOS1 was least expression after $24 \mathrm{~h}$ in the shoots of salt-tolerant Pokkali. Under salt stress, the high expression of OsSOS1 in both Cheongcheong and Nagdong might have led to the discharge of toxic apoplastic $\mathrm{Na}^{+}$from inside the cellular environment, which in turn would have led to better salt tolerance management.

\section{Ion Homeostasis and Combinations Among Rice Genotypes}

Various studies have suggested that salt tolerance is ultimately manifested in plants through several physiological processes. During salt stress, high $\mathrm{Na}^{+}$concentrations outside of plant cells create an electrochemical gradient that facilitates the transport of $\mathrm{Na}^{+}$into the cell through $\mathrm{K}^{+}$transporters, resulting in high cytosolic $\mathrm{Na}^{+}$concentrations (Blumwald, 2000). Salt-stressed plants show high $\mathrm{Na}^{+}$contents and this increase in intracellular $\mathrm{Na}^{+}$results in destructive effects caused by competition with $\mathrm{K}^{+}$ in enzyme activation and protein biosynthesis (Shabala and Cuin, 2008; Wang et al., 2013). Plants under salt stress show not only increased $\mathrm{Na}^{+}$uptake but also reduced $\mathrm{K}^{+}$uptake (Horie et al., 2001; Zhu, 2003). $\mathrm{K}^{+}$ions are important to plants; by increasing $\mathrm{K}^{+}$content, plants can reduce $\mathrm{Na}^{+}$ions to some extent, which thereby reduces the $\mathrm{Na}^{+} / \mathrm{K}^{+}$ratio (Zhang et al., 2018). The extent of salt tolerance in plants is known to be correlated with a more efficient system for the selective uptake of $\mathrm{K}^{+}$over $\mathrm{Na}^{+}$(Noble and Rogers, 1992; Ashraf and O'leary, 1996). In the current study, both $\mathrm{Na}^{+}$and $\mathrm{K}^{+}$ions were significantly increased in the roots and shoots of all four rice genotypes when compared with levels in the control. Among treated plant roots, the $\mathrm{Na}^{+}$ ratio was higher than that of $\mathrm{K}^{+}$in Cheongcheong and IR28, whereas Nagdong and Pokkali had higher $\mathrm{K}^{+}$than $\mathrm{Na}^{+}$thus it might be possible that cultivars Pokkali and Nagdong had more salt-tolerant than that of Cheongcheong and IR28.

A previous study reported a negative relationship between $\mathrm{Mg}^{+}$and $\mathrm{K}^{+}$ions (Valdez-Aguilar et al., 2009). However, in our study, we measured a decrease in $\mathrm{Mg}^{+}$ions rather than $\mathrm{K}^{+}$ions in the roots and shoots of all four treated rice genotypes. High salt absorption interferes with the absorption of other nutrient ions such as $\mathrm{Ca}^{2+}, \mathrm{K}^{+}, \mathrm{N}$, and $\mathrm{P}$, which results in nutritional deficiency and eventually reduced yield and quality (Grattan and Grieve, 1999). We found a significant increase in $\mathrm{Ca}^{2+}$ in the roots and shoots of treated Cheongcheong and IR28 cultivars but a decrease in $\mathrm{Ca}^{2+}$ in the roots of Nagdong and shoots of Pokkali. A previous study reported that mangrove (Bruguiera parviflora) leaves under salt stress cannot alter their endogenous levels of $\mathrm{K}^{+}$and $\mathrm{Fe}^{2+}$ (Parida et al., 2004). However, in our study, we found a significant decrease in $\mathrm{Fe}^{2+}$ in the roots of Cheongcheong and Pokkali and in the shoots of IR28, in contrast to an increase in $\mathrm{Fe}^{2+}$ in the roots and shoots of Nagdong. Similarly, $\mathrm{Fe}^{2+}$ was increased in the roots of IR28 and shoots of Cheongcheong and Pokkali. Achakzai et al. (2010) reported that sunflowers subjected to high doses of salinity increase their uptake of micronutrients including $\mathrm{Cu}^{2+}, \mathrm{Mn}^{2+}$, and $\mathrm{Fe}^{2+}$ in the roots, and $\mathrm{Cu}^{2+}, \mathrm{Fe}^{2+}$, and $\mathrm{Zn}^{2+}$ in the shoots. Salt stress has also been shown to increase the concentration of $\mathrm{Na}^{+}, \mathrm{Ca}^{2+}$, $\mathrm{Mg}^{2+}$, and $\mathrm{Cu}^{2+}$ while decreasing the concentration of $\mathrm{P}$ and $\mathrm{K}^{+}$ in the shoots and straw of IR28 and IR101998-66-2 (Verma and Neue, 1984). In our study, $\mathrm{Zn}^{2+}$ uptake decreased in the roots of Cheongcheong and the roots and shoots of Pokkali under salt stress. On the other hand, $\mathrm{Zn}^{2+}$ uptake increased in the roots and shoots of Nagdong and IR28 and the shoots of Cheongcheong. Salinity stress, also increased $\mathrm{Cu}^{2+}$ uptake in all four genotypes (except in the shoots of IR28, in which a slight reduction was observed). $\mathrm{Mg}^{2+}$ uptake increased in the roots and shoots of all salt-stressed rice genotypes, except in the roots of Cheongcheong. Finally, $\mathrm{Mn}^{2+}$ uptake increased in Cheongcheong, Nagdong, and IR28 roots and shoots but decreased in the roots of Nagdong and roots and shoots of Pokkali.

Given that rice is a staple food facing yield reduction issues caused by environmental stress, climate change, and geographic problems, there is a need to understand how rice cultivars respond to salinity stress. In the present study, Pokkali and Nagdong cultivars were found to have strong salt tolerance during both seed germination and seedling growth. Under 150$\mathrm{mM} \mathrm{NaCl}$ stress, these cultivars showed slight reductions in plant growth, but the plants remained vigorous in comparison to Cheongcheong and the salt-sensitive cultivar IR28. The salt-tolerant varieties Pokkali and Nagdong enhance their salt tolerance by regulating the $\mathrm{Na}^{+} / \mathrm{K}^{+}$ratio in the roots and shoots regions. Under salt stress, ion homeostasis is considered a complex network system that regulates other micronutrients together with OsHKT, OsNHX family, and OsSOS1 genes. Our results indicate that ion transport-related genes and other micronutrients are differentially regulated among rice cultivars under salt stress. In conclusion, growth of the plant molecular breeding lab cultivar Nagdong is superior to that of Cheongcheong under salt stress. The findings of the present study could contribute to the development of high-yielding and salttolerant varieties of rice for plant molecular breeding via the CRISPR/Cas9 system.

\section{DATA AVAILABILITY STATEMENT}

The raw data supporting the conclusions of this article will be made available by the authors, without undue reservation.

\section{AUTHOR CONTRIBUTIONS}

MF planned, designed and performed the research, and analyzed the data and wrote the findings. J-RP contributed to experimental resources. Y-HJ and E-GK contributed to the ICP and statistical analysis. K-MK edited the manuscript. All authors read and approved the final manuscript.

\section{FUNDING}

This work was supported by the National Research Foundation of Korea Grant funded by the Korean Government (NRF-2017R1D1A3B04028676). 


\section{REFERENCES}

Achakzai, A.K. K., Kayani, S. A., and Hanif, A. (2010). Effect of salinity on uptake of micronutrients in sunflower at early vegetative stage. Pak. J. Bot. 42, 129-139.

Al-Harbi, A. R. (1995). Growth and nutrient composition of tomato and cucumber seedlings as affected by sodium chloride salinity and supplemental calcium. J. Plant Nutr. 18, 1403-1416. doi: 10.1080/019041695093 64990

Apse, M. P., Aharon, G. S., Snedden, W. A., and Blumwald, E. (1999). Salt tolerance conferred by overexpression of a vacuolar $\mathrm{Na}+/ \mathrm{H}+$ antiport in Arabidopsis. Science 285, 1256-1258. doi: 10.1126/science.285.5431.1256

Ashraf, M., and O'leary, J. (1996). Responses of some newly developed salt-tolerant genotypes of spring wheat to salt stress: 1. Yield components and ion distribution. J. Agron. Crop Sci. 176, 91-101. doi: 10.1111/j.1439-037X.1996.tb00451.x

Axelsen, K. B., and Palmgren, M. G. (2001). Inventory of the superfamily of P-type ion pumps in Arabidopsis. Plant Physiol. 126, 696-706. doi: $10.1104 /$ pp.126.2.696

Berthomieu, P., Conéjéro, G., Nublat, A., Brackenbury, W. J., Lambert, C., Savio, C., et al. (2003). Functional analysis of AtHKT1 in Arabidopsis shows that $\mathrm{Na}+$ recirculation by the phloem is crucial for salt tolerance. EMBO J. 22, 2004-2014. doi: 10.1093/emboj/cdg207

Blumwald, E. (2000). Sodium transport and salt tolerance in plants. Curr. Opin. Cell Biol. 12, 431-434. doi: 10.1016/S0955-0674(00)00112-5

Cushman, J., Meyer, G., Michalowski, C., Schmitt, J., and Bohnert, H. (1989). Salt stress leads to differential expression of two isogenes of PEPCase during CAM induction in the common Ice plant. Plant Cell 1, 715-725. doi: $10.1105 /$ tpc.1.7.715

Dubey, R. S. (1996). "Photosynthesis in plants under stressful conditions," in Handbook of Photosynthesis (New York, NY: Marcel Dekker), 859-875.

Fukuda, A., Nakamura, A., Hara, N., Toki, S., and Tanaka, Y. (2011). Molecular and functional analyses of rice NHX-type $\mathrm{Na}+/ \mathrm{H}+$ antiporter genes. Planta 233, 175-188. doi: 10.1007/s00425-010-1289-4

Fukuda, A., Nakamura, A., Tagiri, A., Tanaka, H., Miyao, A., Hirochika, H., et al. (2004). Function, intracellular localization and the importance in salt tolerance of a vacuolar $\mathrm{Na}+/ \mathrm{H}+$ antiporter from rice. Plant Cell physiol. 45, 146-159. doi: $10.1093 / \mathrm{pcp} / \mathrm{pch} 014$

García, M. J., Lucena, C., Romera, F. J., Alcántara, E., and Pérez-Vicente, R. (2010). Ethylene and nitric oxide involvement in the up-regulation of key genes related to iron acquisition and homeostasis in Arabidopsis. J. Exp. Bot. 61, 3885-3899. doi: $10.1093 / \mathrm{jxb} / \mathrm{erq} 203$

Garciadeblás, B., Senn, M. E., Bañuelos, M. A., and Rodríguez-Navarro, A. (2003). Sodium transport and HKT transporters: the rice model. Plant J. 34, 788-801. doi: 10.1046/j.1365-313X.2003.01764.x

Gassmann, W., Rubio, F., and Schroeder, J. I. (1996). Alkali cation selectivity of the wheat root high-affinity potassium transporter HKT1. Plant J. 10, 869-882. doi: 10.1046/j.1365-313X.1996.10050869.x

Ghoulam, C., Foursy, A., and Fares, K. (2002). Effects of salt stress on growth, inorganic ions and proline accumulation in relation to osmotic adjustment in five sugar beet cultivars. Environ. Exp. Bot. 47, 39-50. doi: 10.1016/S0098-8472(01)00109-5

Golldack, D., Su, H., Quigley, F., Kamasani, U. R., Muñoz-Garay, C., Balderas, E., et al. (2002). Characterization of a HKT-type transporter in rice as a general alkali cation transporter. Plant J. 31, 529-542. doi: 10.1046/j.1365-313X.2002.01374.x

Grattan, S., and Grieve, C. (1999). Salinity mineral nutrient relations in horticultural crops: a review. Sci. Hortic. 78, 127-157.

Hakim, M., Juraimi, A., Begum, M., Hanafi, M., Ismail, M. R., and Selamat, A. (2010). Effect of salt stress on germination and early seedling growth of rice (Oryza sativa L.). Afr. J. Biotechnol. 9, 1911-1918. doi: 10.5897/AJB09. 1526

Hasegawa, P. M., Bressan, R. A., Zhu, J.-K., and Bohnert, H. J. (2000). Plant cellular and molecular responses to high salinity. Ann. Rev. Plant Biol. 51, 463-499. doi: 10.1146/annurev.arplant.51.1.463

Horie, T., Costa, A., Kim, T. H., Han, M. J., Horie, R., Leung, H. Y., et al. (2007). Rice OsHKT2; 1 transporter mediates large $\mathrm{Na}+$ influx component into $\mathrm{K}+$-starved roots for growth. EMBO J. 26, 3003-3014. doi: 10.1038/sj.emboj.7601732
Horie, T., Motoda, J., Kubo, M., Yang, H., Yoda, K., Horie, R., et al. (2005). Enhanced salt tolerance mediated by AtHKT1 transporter-induced $\mathrm{Na}+$ unloading from xylem vessels to xylem parenchyma cells. Plant J. 44, 928-938. doi: 10.1111/j.1365-313X.2005.02595.x

Horie, T., Yoshida, K., Nakayama, H., Yamada, K., Oiki, S., and Shinmyo, A. (2001). Two types of HKT transporters with different properties of $\mathrm{Na}+$ and $\mathrm{K}+$ transport in Oryza sativa. Plant J. 27, 129-138. doi: 10.1046/j.1365-313x.2001.01077.x

Izzo, R., Navari-Izzo, F., and Quartacci, M. F. (1991). Growth and mineral absorption in maize seedlings as affected by increasing $\mathrm{NaCl}$ concentrations. J. Plant Nutr. 14, 687-699. doi: 10.1080/01904169109364235

Jabnoune, M., Espeout, S., Mieulet, D., Fizames, C., Verdeil, J.-L., Conéjéro, G., et al. (2009). Diversity in expression patterns and functional properties in the rice HKT transporter family. Plant Physiol. 150, 1955-1971. doi: $10.1104 /$ pp.109.138008

Jung, J.-Y., Shin, R., and Schachtman, D. P. (2009). Ethylene mediates response and tolerance to potassium deprivation in Arabidopsis. Plant Cell 21, 607-621. doi: 10.1105/tpc.108.063099

Kader, M. A., Seidel, T., Golldack, D., and Lindberg, S. (2006). Expressions of OsHKT1, OsHKT2, and OsVHA are differentially regulated under $\mathrm{NaCl}$ stress in salt-sensitive and salt-tolerant rice (Oryza sativa L.) cultivars. J. Exp. Bot. 57, 4257-4268. doi: 10.1093/jxb/erl199

Khan, M., Hamid, A., and Karim, M. (1997). Effect of sodium chloride on germination and seedling characters of different types of rice (Oryza sativa L.). J. Agron. Crop Sci. 179, 163-169. doi: 10.1111/j.1439-037X.1997.tb00512.x

Knight, S., Rogers, R., Smith, M., and Sporaer, L. (1992). Effects of $\mathrm{NaCl}$ salinity on miniature dwarf tomato 'Micro-Tom': I. Growth analyses and nutrient composition. J. Plant Nutr. 15, 2315-2327. doi: 10.1080/01904169209364476

Liu, W., Fairbairn, D. J., Reid, R. J., and Schachtman, D. P. (2001). Characterization of two HKT1 homologues from Eucalyptus camaldulensis that display intrinsic osmosensing capability. Plant Physiol. 127, 283-294. doi: 10.1104/pp.127.1.283

Lutts, S., Kinet, J., and Bouharmont, J. (1996). NaCl-induced senescence in leaves of rice (Oryza sativa L.) cultivars differing in salinity resistance. Ann. Bot. 78, 389-398. doi: 10.1006/anbo.1996.0134

Maathuis, F. J., and Amtmann, A. (1999). K+ nutrition and Na+ toxicity: the basis of cellular K+/Na+ ratios. Ann. Bot. 84, 123-133. doi: 10.1006/anbo.1999.0912

Mäser, P., Eckelman, B., Vaidyanathan, R., Horie, T., Fairbairn, D. J., Kubo, M., et al. (2002). Altered shoot/root $\mathrm{Na}+$ distribution and bifurcating salt sensitivity in Arabidopsis by genetic disruption of the $\mathrm{Na}+$ transporter AtHKT1. FEBS Lett. 531, 157-161. doi: 10.1016/S0014-5793(02)03488-9

Masutomi, Y., Takahashi, K., Harasawa, H., and Matsuoka, Y. (2009). Impact assessment of climate change on rice production in Asia in comprehensive consideration of process/parameter uncertainty in general circulation models. Agric. Ecosyst. Environ. 131, 281-291. doi: 10.1016/j.agee.2009.02.004

Meloni, D. A., Oliva, M. A., Ruiz, H. A., and Martinez, C. A. (2001). Contribution of proline and inorganic solutes to osmotic adjustment in cotton under salt stress. J. Plant Nutr. 24, 599-612. doi: 10.1081/PLN-100104983

Munns, R., and Tester, M. (2008). Mechanisms of salinity tolerance. Annu. Rev. Plant Biol. 59, 651-681. doi: 10.1146/annurev.arplant.59.032607.092911

Nass, R., and Rao, R. (1998). Novel localization of a $\mathrm{Na}+/ \mathrm{H}+$ exchanger in a late endosomal compartment of yeast implications for vacuole biogenesis. J. Biol. Chem. 273, 21054-21060. doi: 10.1074/jbc.273.33.21054

Niazi, B., and Ahmed, T. (1984). Effect of sodium chloride and zinc on the growth of tomato. II. Uptake of ions. Geobios 11, 155-160.

Noble, C., and Rogers, M. (1992). Arguments for the use of physiological criteria for improving the salt tolerance in crops. Plant Soil 146, 99-107. doi: 10.1007/BF00012001

Ologundudu, A. F., Adelusi, A. A., and Akinwale, R. O. (2014). Effect of Salt Stress on Germination and Growth Parameters of Rice (Oryza sativa L.). Notulae Scientia Biologicae 6, 237-243. doi: 10.15835/nsb.6.2.9163

Orlowski, J., and Grinstein, S. (1997). Na+/H+ exchangers of mammalian cells. Journal of Biological Chemistry 272, 22373-22376. doi: 10.1074/jbc.272.36.22373

Page, A. (1996). Deficiencies and toxicities of trace elements. Agricultural Salinity Assessment and Management. ASCE Manuals Rep. Eng. Pract. 71, 138-160.

Pardo, J. M., Cubero, B., Leidi, E. O., and Quintero, F. J. (2006). Alkali cation exchangers: roles in cellular homeostasis and stress tolerance. J. Exp. Bot. 57, 1181-1199. doi: 10.1093/jxb/erj114 
Parida, A. K., Das, A., and Mittra, B. (2004). Effects of salt on growth, ion accumulation, photosynthesis and leaf anatomy of the mangrove, Bruguiera parviflora. Trees 18, 167-174. doi: 10.1007/s00468-003-0293-8

Plaut, Z., Edelstein, M., and Ben-Hur, M. (2013). Overcoming salinity barriers to crop production using traditional methods. CRC. Crit. Rev. Plant Sci. 32, 250-291. doi: 10.1080/07352689.2012.752236

Rahman, S., Vance, G., and Munn, L. (1993). Salinity induced effects on the nutrient status of soil, corn leaves and kernels. Commun. Soil Sci. Plant Anal. 24, 2251-2269. doi: 10.1080/00103629309368953

Ren, Z.-H., Gao, J.-P., Li, L.-G., Cai, X.-L., Huang, W., Chao, D.-Y., et al. (2005). A rice quantitative trait locus for salt tolerance encodes a sodium transporter. Nat. Gene. 37, 1141-1146. doi: 10.1038/ng1643

Romero-Aranda, R., Soria, T., and Cuartero, J. (2001). Tomato plant-water uptake and plant-water relationships under saline growth conditions. Plant Sci. 160, 265-272. doi: 10.1016/S0168-9452(00)00388-5

Roy, S. J., Negrão, S., and Tester, M. (2014). Salt resistant crop plants. Curr. Opin. Biotechnol. 26, 115-124. doi: 10.1016/j.copbio.2013.12.004

Ruiz, D., Martínez, V., and Cerd,á, A. (1997). Citrus response to salinity: growth and nutrient uptake. Tree Physiol. 17, 141-150. doi: 10.1093/treephys/ 17.3.141

Rus, A., Yokoi, S., Sharkhuu, A., Reddy, M., Lee, B.-H., Matsumoto, T. K., et al. (2001). AtHKT1 is a salt tolerance determinant that controls $\mathrm{Na}+$ entry into plant roots. Proc. Natl. Acad. Sci. 98, 14150-14155. doi: $10.1073 /$ pnas. 241501798

Schachtman, D. P., and Schroeder, J. I. (1994). Structure and transport mechanism of a high-affinity potassium uptake transporter from higher plants. Nature 370, 655-658. doi: 10.1038/370655a0

Shabala, S., and Cuin, T. A. (2008). Potassium transport and plant salt tolerance. Physiol. Plantarum 133, 651-669. doi: 10.1111/j.1399-3054.2007. 01008.x

Shi, H., Ishitani, M., Kim, C., and Zhu, J.-K. (2000). The Arabidopsis thaliana salt tolerance gene SOS1 encodes a putative $\mathrm{Na}+/ \mathrm{H}+$ antiporter. Proc. Natl. Acad. Sci. 97, 6896-6901. doi: 10.1073/pnas.120170197

Shi, H., Quintero, F. J., Pardo, J. M., and Zhu, J.-K. (2002). The putative plasma membrane $\mathrm{Na}+/ \mathrm{H}+$ antiporter SOS1 controls long-distance $\mathrm{Na}+$ transport in plants. Plant Cell 14, 465-477. doi: 10.1105/tpc.010371

Sirault, X. R., James, R. A., and Furbank, R. T. (2009). A new screening method for osmotic component of salinity tolerance in cereals using infrared thermography. Funct. Plant Biol. 36, 970-977. doi: 10.1071/FP 09182

Su, H., Balderas, E., Vera-Estrella, R., Golldack, D., Quigley, F., Zhao, C., et al. (2003). Expression of the cation transporter McHKT1 in a halophyte. Plant Mol. Biol. 52, 967-980. doi: 10.1023/A:1025445612244

Taiz, L., and Zeiger, E. (1998). Plant Physiology, 2nd Edn. Saunderland, MA: Sinauer Associates. Inc., Publ. 792.

Taiz, L., and Zeiger, E. (2002). Plant Physiology. Sunderland, MA: Sinauer Associates, Inc., Publishers. 3-484.

Tunçturk, M., Tunçturk, R., and Yasar, F. (2008). Changes in micronutrients, dry weight and plant growth of soybean (Glycine max L. Merrill) cultivars under salt stress. Afr. J. Biotechnol. 7, 650-1654. doi: 10.5897/AJB08. 248

Tuteja, N., Sahoo, R. K., Garg, B., and Tuteja, R. (2013). O s SUV 3 dual helicase functions in salinity stress tolerance by maintaining photosynthesis and antioxidant machinery in rice (Oryza sativa L. cv. IR 64). Plant J. 76, 115-127. doi: 10.1111/tpj.12277

Valdez-Aguilar, L. A., Grieve, C. M., and Poss, J. (2009). Salinity and alkaline $\mathrm{pH}$ in irrigation water affect marigold plants: I. Growth and shoot dry weight partitioning. HortScience 44, 1719-1725. doi: 10.21273/HORTSCI.44.6.1719

Van Genuchten, M. T., and Gupta, S. (1993). A reassessment of the crop tolerance response function. J. Indian Soc. Soil Sci. 41, 730-737.

Verma, T., and Neue, H. (1984). Effect of soil salinity level and zinc application on growth, yield, and nutrient composition of rice. Plant Soil 82, 3-14. doi: 10.1007/BF02220765

Wahome, P., Jesch, H., and Grittner, I. (2001). Mechanisms of salt stress tolerance in two rose rootstocks: Rosa chinensis 'Major'and R. rubiginosa. Sci. Hortic. 87, 207-216. doi: 10.1016/S0304-4238(00)00168-0

Wang, M., Zheng, Q., Shen, Q., and Guo, S. (2013). The critical role of potassium in plant stress response. Int. J. Mol. Sci. 14, 7370-7390. doi: 10.3390/ijms 14047370

Wu, S.-J., Ding, L., and Zhu, J.-K. (1996). SOS1, a genetic locus essential for salt tolerance and potassium acquisition. Plant Cell 8, 617-627. doi: $10.2307 / 3870339$

Yun, B.-W., Kim, M.-G., Handoyo, T., and Kim, K.-M. (2014). Analysis of rice grain quality-associated quantitative trait loci by using genetic mapping. Am. J. Plant Sci. 5:1125. doi: 10.4236/ajps.2014.59125

Zhang, Y., Fang, J., Wu, X., and Dong, L. (2018). Na+/K+ balance and transport regulatory mechanisms in weedy and cultivated rice (Oryza sativa L.) under salt stress. BMC plant Biol. 18, 1-14. doi: 10.1186/s12870-018-1586-9

Zhu, J.-K. (2003). Regulation of ion homeostasis under salt stress. Curr. Opin. Plant Biol. 6, 441-445. doi: 10.1016/S1369-5266(03)00085-2

Conflict of Interest: The authors declare that the research was conducted in the absence of any commercial or financial relationships that could be construed as a potential conflict of interest.

Publisher's Note: All claims expressed in this article are solely those of the authors and do not necessarily represent those of their affiliated organizations, or those of the publisher, the editors and the reviewers. Any product that may be evaluated in this article, or claim that may be made by its manufacturer, is not guaranteed or endorsed by the publisher.

Copyright (c) 2021 Farooq, Park, Jang, Kim and Kim. This is an open-access article distributed under the terms of the Creative Commons Attribution License (CC BY). The use, distribution or reproduction in other forums is permitted, provided the original author(s) and the copyright owner(s) are credited and that the original publication in this journal is cited, in accordance with accepted academic practice. No use, distribution or reproduction is permitted which does not comply with these terms. 